\title{
Real-World Characteristics and Treatment Patterns in Patients with Urticaria Initiating Omalizumab in the United States
}

\author{
Xuehua Ke, PhD; Abhishek Kavati, PhD; Debra Wertz, PharmD; Qing Huang, PhD; Liya Wang, PhD; \\ Vincent J. Willey, PharmD; Judith J. Stephenson, SM; Benjamin Ortiz, MD; Brandee Paknis, PharmD; \\ Jonathan A. Bernstein, MD; and Lisa A. Beck, MD
}

\begin{abstract}
BACKGROUND: Omalizumab is indicated for the management of chronic idiopathic urticaria (CIU) in patients aged 12 years or older with persistent hives that are not adequately controlled by $\mathrm{H} 1$ antihistamines. While its safety and efficacy in CIU patients have been evaluated in multiple clinical trials, real-world use of omalizaumab in CIU has not been well characterized.
\end{abstract}

OBJECTIVE: To assess demographics, clinical characteristics, and treatment patterns of CIU patients who initiated omalizumab to better understand the usage of this agent in CIU management in the real world.

METHODS: This retrospective cohort study used medical and pharmacy claims data in the United States from the HealthCore Integrated Database to identify patients with CIU newly treated with omalizumab ( $\geq 4$ omalizumab claims within 6 months of the initial claim) between March 21, 2014, and 0ctober 31, 2015 (study intake period). The index date was defined as the date of the first claim for omalizumab during the study intake period. Demographic and clinical characteristics were described for patients treated with omalizumab, as were treatment patterns associated with omalizumab and concomitant medications associated with CIU treatment. Descriptive and inferential statistics were reported. The Kaplan-Meier method was used to examine omalizumab treatment patterns.

RESULTS: This study included 298 omalizumab-treated patients (mean [SD] age of 43.5 [13.64] years; $70.8 \%$ female); approximately $84 \%$ were seen by an allergist/immunologist. All patients had $\geq 12$ months of continuous enrolment and a subset of 138 patients had $\geq 18$ months of follow-up. For patients with $\geq 12$ months of post-index follow-up, $12.1 \%(n=36), 28.5 \%$ $(n=85)$, and $32.9 \%(n=98)$ discontinued omalizumab within the 6-month, 12-month, and the entire post-index periods (mean 530 days), respectively; the mean number of days patients were continuously treated with omalizumab was $443.1(95 \% \mathrm{Cl}=425.0-461.3)$; the probabilities of continuous treatment $(95 \% \mathrm{Cl})$ were $0.879(0.836-0.911), 0.711(0.656-0.759)$, and $0.647(0.585-0.703)$ for the $6-, 12-$, and 18 -month post-index periods, respectively. For the 98 patients who discontinued omalizumab during the entire post-index period, $28.6 \%$ restarted omalizumab after the first discontinuation within the post-index period (mean time from first discontinuation to first restart $=329$ days). Use of medications such as oral corticosteroids, montelukast, cyclosporine, and prescription $\mathrm{H} 1$ and $\mathrm{H} 2$ antihistamines decreased during the 1- to 6-month and 7- to 12-month post-index periods compared with those within the 6-month pre-index period.

CONCLUSIONS: In this cohort of CIU patients who were newly prescribed omalizumab, the majority were treated by allergists/immunologists as expected, and approximately $60 \%$ of patients continued on therapy beyond 18 months. Concomitant medication use decreased after omalizumab initiation. These data on the real-world use of omalizumab for CIU may help to better inform decision-making processes for health care payers by quantifying omalizumab and concomitant medication treatment patterns over a longer time frame relative to previous studies.

J Manag Care Spec Pharm. 2018;24(7):598-606

Copyright $\odot 2018$, Academy of Managed Care Pharmacy. All rights reserved.

\section{What is already known about this subject}

A step-care approach has been developed for management of chronic idiopathic urticaria (CIU).

Safety and efficacy data regarding use of omalizumab in CIU patients are available from multiple randomized clinical trials.

Outcomes data are available from very few retrospective observational studies with short follow-up periods, studies with relatively small sample sizes, or studies performed outside of the United States.

\section{What this study adds}

This study provides information on real-world treatment patterns for omalizumab in the United States for longer periods than previously reported in clinical trials.

Long-term real-world data are reported on changes in clinical characteristics and concomitant medication use among CIU patients initiating omalizumab in the United States.

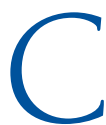
hronic idiopathic urticaria (CIU), also referred to as chronic spontaneous urticaria, is characterized by the appearance of either itchy hives or angioedema or both without any detectable cause that persist for at least 6 weeks. ${ }^{1-4}$ The symptoms of CIU, which include swelling of the skin, significant itching, pain in affected areas, and general discomfort, are unpredictable and variable and may continue for periods lasting several months to years., ${ }^{3,5}$ Currently, an estimated 1.5 million people are affected by CIU in the United States., ${ }^{4,6}$ CIU occurs twice as frequently among women compared with men in the general population and symptoms typically begin between 20 and 40 years of age..$^{4,7}$

The management of CIU relies on a stepwise approach. ${ }^{2,8,9}$ Second-generation $\mathrm{Hl}$ antihistamines are regarded as first-line treatment for CIU and appear to be effective in a large segment of the patient population; however, as many as $50 \%$ of patients have an inadequate response and fail to achieve complete control, ${ }^{4}$ even when dosing was increased up to 4 -fold above standard doses., ${ }^{28-10} \mathrm{H} 2$ antihistamines or leukotriene receptor antagonists (LTRAs) such as montelukast, combined with second-generation $\mathrm{Hl}$ antihistamines, are considered second-line treatment for patients with persistently severe urticaria despite 
high-dose $\mathrm{Hl}$ antihistamine treatment as described in the Joint Task Force on Practice Parameters /American Academy of Allergy, Asthma \& Immunology/American College of Allergy, Asthma \& Immunology document. ${ }^{8}$ However, urticaria does not always improve with combined treatment, especially among patients with severe urticaria. ${ }^{10}$

Omalizumab, a monoclonal antibody directed against IgE, ${ }^{11}$ was approved in the United States for uncontrolled moderate to severe persistent allergic asthma in 2003 and became a treatment option for CIU after U.S. Food and Drug Administration (FDA) approval on March 21, 2014. It is indicated for CIU in adults and children 12 years of age or older who remain symptomatic despite treatment with $\mathrm{Hl}$ antihistamines. ${ }^{12}$ The package insert states that the appropriate duration of therapy has not been evaluated and that the need for continued therapy should be reassessed periodically. The safety and efficacy of omalizumab in treating CIU have been evaluated in multiple clinical trials. ${ }^{11,13-15}$ In three phase 3 studies, ASTERIA II, ${ }^{14}$ GLACIAL, ${ }^{15}$ and ASTERIA I ${ }^{16}$ CIU symptoms were reduced after patients were treated with omalizumab. Postapproval data are only available from a handful of small, short-duration, observational studies, mostly conducted outside the United States. , $^{517-19}$

As a result, information on the real-world treatment experience of patients receiving omalizumab for CIU is deficient. Specifically, data are lacking on the interval between courses of treatment with omalizumab and how omalizumab is used as a long-term therapy for managing CIU. ${ }^{2,8,9}$ This study examined patient demographics, clinical characteristics, and treatment patterns among CIU patients initiating omalizumab to better understand real-world use of this agent in the management of CIU patients. While this study focused largely on patients with $\geq 12$ months of follow-up, it also reports findings from a subset of patients with $\geq 18$ months of follow-up to gain insights into longer treatment periods.

\section{Methods}

\section{Study Design}

This observational cohort study queried medical and pharmacy claims data, curated in the HealthCore Integrated Database (HIRD), for patients with CIU who initiated omalizumab treatment between March 21, 2014, and October 31, 2015. The HIRD is a repository of longitudinal administrative claims data for enrollees in 14 major regional health plans and is largely representative of the U.S. Census population. ${ }^{20}$ The date of the first claim for omalizumab during the study intake period was defined as the index date and the full time period of the study was from September 20, 2013, to April 30, 2016. All study data were managed in strict compliance with applicable Health Insurance Portability and Accountability ACT (HIPAA) rules, and data deidentification procedures were employed to preserve patient anonymity and confidentiality throughout the study process.

\section{Study Population and Eligibility Criteria}

Patients who satisfied the study definition of omalizumab treatment, ${ }^{7}$ defined as at least 4 medical or pharmacy claims of omalizumab (Current Procedural Terminology code: J2357; General Product Identifier code: 44603060002120) within the 6 -month post-index period, were included. The number of medical and pharmacy claims was determined from distinct claim dates for omalizumab. Only patients with CIU in the study period were included. This was defined as $\geq 1$ medical claim for an inpatient stay or emergency department (ED) visit with an International Classification of Diseases, Ninth Revision, Clinical Modification (ICD-9-CM) or International Classification of Diseases, Tenth Revision, Clinical Modification (ICD-10-CM) diagnosis code for urticaria (ICD-9-CM diagnosis codes: 708.xx; ICD-10-CM diagnosis codes: L50.0-L50.9) in the primary diagnosis position or with $\geq 2$ medical claims with distinct service dates for urticaria in any position of the claims in any setting. This approach was used because of the absence of a specific ICD code for CIU and considering that study patients were enrollees in Anthem health plans that required prior authorization based on verification of CIU status before approving omalizumab treatment. Study patients were aged $\geq 12$ years on the index date; had $\geq 6$ months of continuous health plan eligibility immediately preceding the index date; had 12 months of continuous health plan eligibility following the index date; and were enrolled in a commercial or Medicare Advantage health plan during the entire study period. Patients with any claims for omalizumab in the pre-index period were excluded.

\section{Study Measures}

Demographics. Demographic variables including age, gender, health plan type, Medicare Advantage Plan indicator, and patient geographic region were based on patient information on the index date.

Clinical Characteristics. The clinical characteristics of interest for the 6-month pre-index (baseline) period and for the 2 or 3 post-index periods (i.e., 1- to 6-month, 7-to 12-month, and 13- to 18-month follow-up [for patients with $\geq 18$ months of follow-up]) included provider specialty and conditions such as allergic rhinitis, anaphylaxis, conjunctivitis, eczema/dermatitis, food allergy, angioedema, asthma, chronic obstructive pulmonary disease, anxiety, depression, vasculitis, and allergic purpura, which were identified by requiring at least 1 medical claim with specific diagnosis codes of interest. Breakdown categories of urticaria based on ICD-9-CM/ICD-10-CM codes and laboratory tests of interest were also evaluated. 


\begin{tabular}{|c|c|c|}
\hline Demographic Characteristics $^{a}$ & $\begin{array}{l}\text { Patients with } \\
\geq 12 \text { Months of } \\
\text { Follow-up } \\
\mathrm{n}=298\end{array}$ & $\begin{array}{l}\text { Patients with } \\
\geq 18 \text { Months of } \\
\text { Follow-up } \\
\mathrm{n}=138\end{array}$ \\
\hline Female, n (\%) & $211 \quad(70.8)$ & $97 \quad(70.3)$ \\
\hline Age at index (years), mean (SD) & $43.5(13.64)$ & $43.4(14.00)$ \\
\hline \multicolumn{3}{|l|}{ Age categories, n (\%) } \\
\hline $12-17$ & $(6.4)$ & $(8.0)$ \\
\hline $18-39$ & $84 \quad(28.2)$ & $34 \quad(24.6)$ \\
\hline $40-64$ & $180 \quad(60.4)$ & $84 \quad(60.9)$ \\
\hline $65-74$ & $13 \quad(4.4)$ & $7 \quad(5.1)$ \\
\hline $75+$ & $2 \quad(0.7)$ & $(1.4)$ \\
\hline \multicolumn{3}{|l|}{ Health plan type, n (\%) } \\
\hline $\mathrm{HMO}$ & $73 \quad(24.5)$ & $38 \quad(27.5)$ \\
\hline $\mathrm{PPO}$ & $186 \quad(62.4)$ & $82 \quad(59.4)$ \\
\hline CDHP & $38 \quad(12.8)$ & $18 \quad(13.0)$ \\
\hline Other & $(0.3)$ & $(0.0)$ \\
\hline MA plan, n (\%) & $(1.3)$ & $(2.2)$ \\
\hline \multicolumn{3}{|l|}{ Geographic region of patient, n (\%) } \\
\hline Northeast & $47 \quad(15.8)$ & $25 \quad(18.1)$ \\
\hline Midwest & $83 \quad(27.9)$ & $42 \quad(30.4)$ \\
\hline South & $96 \quad(32.2)$ & $40 \quad(29.0)$ \\
\hline West & $72 \quad(24.2)$ & $31 \quad(22.5)$ \\
\hline \multicolumn{3}{|l|}{ Year of index date, $n(\%)$} \\
\hline 2014 & $202 \quad(67.8)$ & $138(100.0)$ \\
\hline 2015 & $96 \quad(32.2)$ & $\begin{array}{ll}0 & (0.0) \\
\end{array}$ \\
\hline \multicolumn{3}{|c|}{$\begin{array}{l}\text { aAssessed on index date. } \\
C I U=\text { chronic idiopathic urticaria } ; C D H P=\text { consumer } \text { driven health plan; } \\
\text { HMO=health maintenance organization; } M A=\text { Medicare Advantage; } \\
P P O=\text { preferred provider organization; } S D=\text { standard deviation. }\end{array}$} \\
\hline
\end{tabular}

Treatment Patterns. The use of medications was evaluated for the baseline period and during the 2 or 3 post-index periods (i.e., 1- to 6-month, 7- to 12-month, and 13- to 18-month follow-up [for patients with $\geq 18$ months of follow-up]) for first-, second-, and third-line therapies including prescription $\mathrm{H} 1$ and $\mathrm{H} 2$ antihistamines, montelukast, cyclosporine, oral corticosteroids, hydroxychloroquine, and omalizumab. For omalizumab, usage was reported for continuously treated patients and for those who stopped omalizumab therapy during the 6-, 12-, 18-month, and entire post-index periods (maximum $=754$ days $[\sim 25$ months $]$ ). The proportions of patients who restarted after stopping the first course of treatment during the 6-, 12-, and 18-month periods were also reported. Treatment discontinuation, only reported for the first interruption after the index date, was defined as a gap of $\geq 90$ days after treatment administration/fill, in accordance with guidance from the study's medical advisors and based on clinical experience. A sensitivity analysis using a gap of $\geq 60$ days was also conducted. The discontinuation date was defined as the last date omalizumab was administered within the first continuous therapy segment plus 1 day for medical claims or the last fill date plus days supply of the last fill for pharmacy claims. Continuous omalizumab treatment (measured in days) was defined as the time from the index date to the discontinuation date. For patients without treatment interruption, the duration of continuous treatment was defined as the entire post-index follow-up period. The restart date was defined as the date of first omalizumab claim following a treatment discontinuation.

\section{Statistical Analysis}

Descriptive statistics including means (standard deviation [SD]) for continuous variables and relative frequencies for categorical variables were reported. An unadjusted analysis was conducted for all comparisons between the 6-month pre-index period and the 3 post-index periods. $P$ values were estimated using paired t-tests for normally distributed variables, Wilcoxon signed-rank sum tests for non-normally distributed continuous variables, or McNemar tests (or Bowker's test of symmetry for square tables larger than $2 \times 2$ ) for categorical variables. The Kaplan-Meier method was used to examine continuous omalizumab treatment until the first discontinuation or end of study follow-up, whichever occurred first. Omalizumab restart from the first discontinuation date until the first restart date or end of study follow-up, whichever occurred first, was also assessed with the Kaplan-Meier method for the subset of patients who discontinued omalizumab. All analyses were performed with SAS Enterprise Guide 7.1 (SAS Institute, Cary, NC); a 2-sided $5 \%$ significance level was used for all statistical tests.

\section{Results}

\section{Sample Size}

Among 2,001 patients who initiated omalizumab within the intake period, 1,026 patients had the diagnosis code for CIU. Among these, a total of 408 patients had enrollment in only commercial or Medicare Advantage plans during the study period; had $\geq 6$ months pre-index and $\geq 12$ months post-index continuous health plan enrollment; and were $\geq 12$ years of age as of index date. Among these 408 patients, 298 satisfied the requirements for $\geq 4$ omalizumab medical or pharmacy claims within the first 6 -month post-index period and had $\geq 12$ months of health insurance eligibility, and 138 of the 298 patients had $\geq 18$ months of health insurance eligibility.

\section{Demographic Characteristics}

Study patients had a mean (SD) age of 43.5 (13.64) years, and $70.8 \%$ were female. The subgroup of patients with $\geq 18$ months were similar, with a mean (SD) age of 43.4 (14.00) years, with $70.3 \%$ female. The $40-64$ years age group made up the largest proportion of patients in both the full study population (60.4\%) and the subset $(60.9 \%)$ of patients with $\geq 18$ months of followup, as shown in Table 1. 
TABLE 2 Pre- and Post-Index Clinical Characteristics for Patients with CIU Initiating Omalizumab and with $\geq 12$ Months of Follow-up ( $N=298$ )

\begin{tabular}{|c|c|c|c|c|c|}
\hline Clinical Characteristics & $\begin{array}{c}6 \text { Months } \\
\text { Pre-Index (A) }\end{array}$ & $\begin{array}{c}6 \text { Months } \\
\text { Post-Index (B) }\end{array}$ & $\begin{array}{l}\text { 7-12 Months } \\
\text { Post-Index (C) }\end{array}$ & $\begin{array}{l}P \text { Value }^{\mathrm{a}} \\
\text { (A vs. B) }\end{array}$ & $\begin{array}{l}P \text { Value } \\
\text { (A vs. C) }\end{array}$ \\
\hline Prescribing/treating physician specialty, ${ }^{\mathrm{b}}$ n (\%) & & & & 0.615 & 0.118 \\
\hline Allergist/immunologist & $249(83.6)$ & $249(83.6)$ & $231(77.5)$ & 1.000 & 0.004 \\
\hline Dermatologist & $17 \quad(5.7)$ & $13 \quad(4.4)$ & $16 \quad(5.4)$ & 0.102 & 0.655 \\
\hline PCP & $7 \quad(2.3)$ & $4 \quad(1.3)$ & $7 \quad(2.3)$ & 0.257 & 1.000 \\
\hline Other & $14 \quad(4.7)$ & $17 \quad(5.7)$ & $17 \quad(5.7)$ & 0.366 & 0.439 \\
\hline Unknown & $11 \quad(3.7)$ & $15 \quad(5.0)$ & $27 \quad(9.1)$ & 0.157 & 0.002 \\
\hline \multicolumn{6}{|l|}{ Comorbidities of interest, $n(\%)$} \\
\hline Allergic rhinitis & $143(48.0)$ & $121(40.6)$ & $112(37.6)$ & 0.008 & $<0.001$ \\
\hline Anaphylaxis & $13 \quad(4.4)$ & $4 \quad(1.3)$ & $2 \quad(0.7)$ & 0.029 & 0.002 \\
\hline Conjunctivitis & $19 \quad(6.4)$ & $20 \quad(6.7)$ & $14 \quad(4.7)$ & 0.827 & 0.275 \\
\hline Eczema/dermatitis & $68(22.8)$ & $45(15.1)$ & $38(12.8)$ & 0.004 & $<0.001$ \\
\hline Food allergy & $14 \quad(4.7)$ & $9 \quad(3.0)$ & $6 \quad(2.0)$ & 0.166 & 0.046 \\
\hline Angioedema & $88 \quad(29.5)$ & $59(19.8)$ & $39(13.1)$ & $<0.001$ & $<0.001$ \\
\hline Asthma & $77(25.8)$ & $129(43.3)$ & $106(35.6)$ & $<0.001$ & $<0.001$ \\
\hline COPD & $3 \quad(1.0)$ & $5 \quad(1.7)$ & $4 \quad(1.3)$ & 0.157 & 0.564 \\
\hline Anxiety & $34(11.4)$ & $36(12.1)$ & $27 \quad(9.1)$ & 0.752 & 0.250 \\
\hline Depression & $9 \quad(3.0)$ & $8 \quad(2.7)$ & $19 \quad(6.4)$ & 0.705 & 0.018 \\
\hline Vasculitis and allergic purpura & $0 \quad(0.0)$ & $1 \quad(0.3)$ & $2 \quad(0.7)$ & 0.317 & 0.157 \\
\hline \multicolumn{6}{|l|}{ Breakdown categories of urticaria, ${ }^{\mathrm{c}} \mathbf{n}(\%)$} \\
\hline Overall urticaria & $283(95.0)$ & $286(96.0)$ & $265(88.9)$ & 0.467 & 0.004 \\
\hline Allergic urticaria & $68(22.8)$ & $54(18.1)$ & $40 \quad(13.4)$ & 0.075 & $<0.001$ \\
\hline Idiopathic urticaria & $146(49.0)$ & $180(60.4)$ & $180(60.4)$ & $<0.001$ & $<0.001$ \\
\hline Urticaria due to cold and heat & $4 \quad(1.3)$ & $5 \quad(1.7)$ & $4 \quad(1.3)$ & 0.655 & 1.000 \\
\hline Dermatographic urticaria & $23 \quad(7.7)$ & $12 \quad(4.0)$ & $13 \quad(4.4)$ & 0.012 & 0.033 \\
\hline Vibratory urticaria & $0 \quad(0.0)$ & $0 \quad(0.0)$ & $0 \quad(0.0)$ & - & - \\
\hline Cholinergic urticaria & $5 \quad(1.7)$ & $3 \quad(1.0)$ & $4 \quad(1.3)$ & 0.317 & 0.655 \\
\hline Other specified urticaria & $136(45.6)$ & $125(41.9)$ & $104(34.9)$ & 0.192 & $<0.001$ \\
\hline Urticaria, unspecified & $158(53.0)$ & $117 \quad(39.3)$ & $91 \quad(30.5)$ & $<0.001$ & $<0.001$ \\
\hline \multicolumn{6}{|l|}{ Laboratory tests of interest, $n(\%)$} \\
\hline CBC test & $144(48.3)$ & $90(30.2)$ & $95 \quad(31.9)$ & $<0.001$ & $<0.001$ \\
\hline ESR test & $90(30.2)$ & $29 \quad(9.7)$ & $36(12.1)$ & $<0.001$ & $<0.001$ \\
\hline Thyroid antibody test & $71 \quad(23.8)$ & $17 \quad(5.7)$ & $16 \quad(5.4)$ & $<0.001$ & $<0.001$ \\
\hline \multicolumn{6}{|c|}{$\begin{array}{l}\text { aP values were estimated from paired t-tests or Wilcoxon signed-rank sum tests for normally distributed and non-normally distributed continuous variables, respectively, } \\
\text { and from McNemar tests (or Bowker's tests of symmetry for square tables larger than } 2 \times 2 \text { ) for categorical variables. } \\
\text { bThe following hierarchy was applied when multiple specialties existed: allergy/immunology }>\text { dermatology }>\text { family/general practice }>\text { internal medicine }>\text { others or } \\
\text { unknown. PCP includes family/general practice and internal medicine. } \\
\text { 'All patients had urticaria claims during the study period; however, not all patients had urticaria claims during both the pre-index and post-index periods reported here } \\
C B C=\text { complete blood count with differential; CIU =chronic idiopathic urticaria; COPD =chronic obstructive pulmonary disease; ESR=erythrocyte sedimentation rate; } \\
P C P=\text { primary care provider. }\end{array}$} \\
\hline
\end{tabular}

\section{Pre- and Post-Index Clinical Characteristics}

Provider Type. A majority of patients with $\geq 12$ months of follow-up were seen by allergists/immunologists in the 6-month pre-index (83.6\%), 6-month post-index (83.6\%), and 7- to 12 -month post-index (77.5\%) periods. Across those periods, $5.7 \%, 4.4 \%$, and $5.4 \%$ of patients were seen by dermatologists and $2.3 \%, 1.3 \%$, and $2.3 \%$ were seen by primary care physicians, respectively, as shown in Table 2. A similar pattern was seen for patients with $\geq 18$ months of follow-up as shown in Appendix A (available in online article).
Comorbidities. Medical claims submitted during the preindex baseline and 2 post-index periods decreased significantly across all 3 time periods (baseline, 1- to 6-month, and 7- to 12-month; all comparisons, $P<0.05)$ for allergic rhinitis ( $48.0 \%$ vs. $40.6 \%$ vs. $37.6 \%$ ), anaphylaxis ( $4.4 \%$ vs. $1.3 \%$ vs. $0.7 \%$ ), eczema/dermatitis ( $22.8 \%$ vs. $15.1 \%$ vs. $12.8 \%$ ), and angioedema (29.5\% vs. $19.8 \%$ vs. $13.1 \%$ ), as shown in Table 2 . Similar trends were observed in patients with $\geq 18$ months of post-index follow-up and continued over the longer follow-up time period (e.g., months 13-18) as shown in Appendix A. 


\section{FIGURE 1 Pre- and Post-Index Concomitant Medication Use for Patients with CIU Initiating Omalizumab and} with $\geq 12$ Months of Follow-up $(\mathrm{N}=298)$

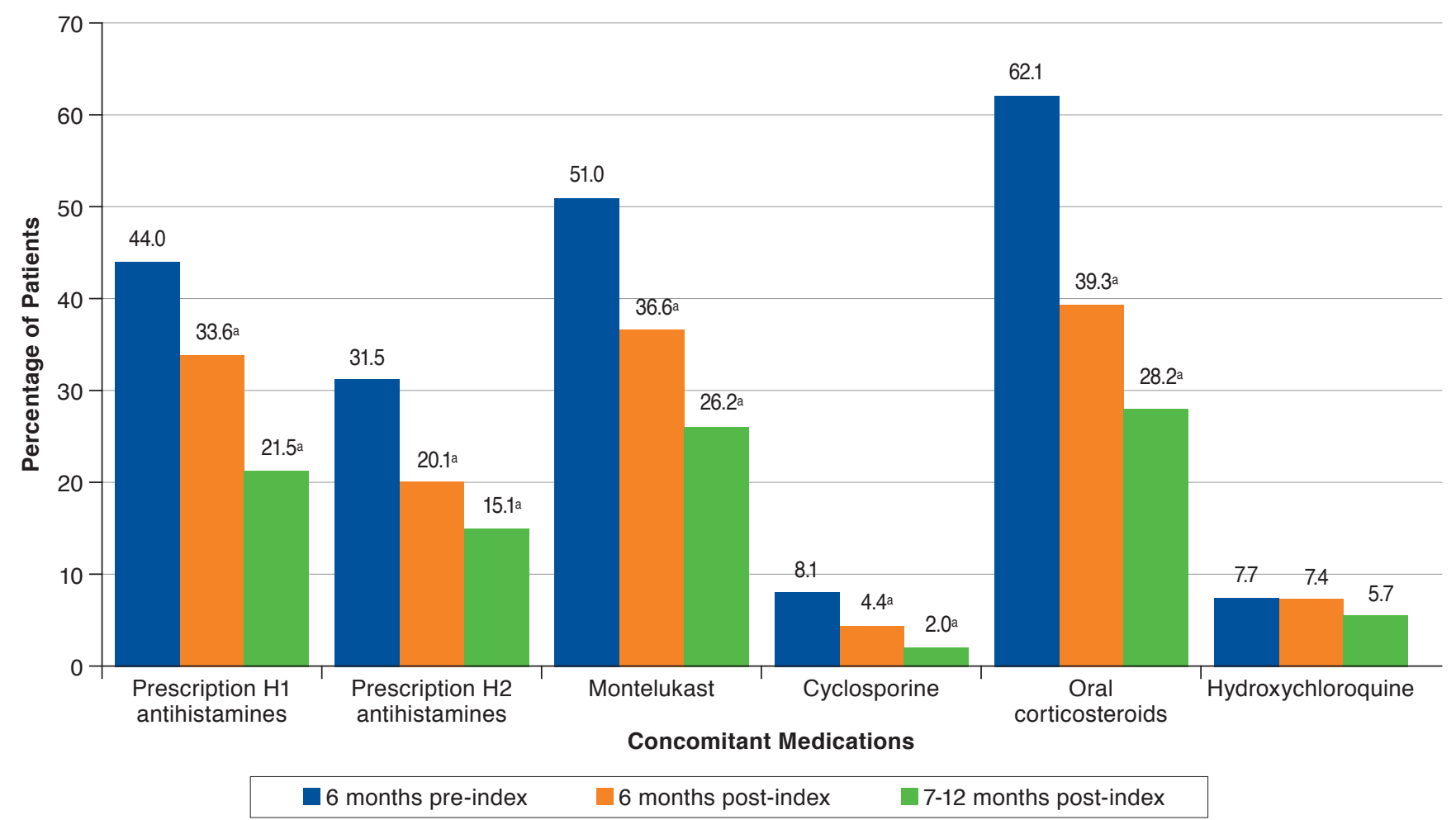

${ }^{a} P<0.05$ when comparing post-index with pre-index periods.

$\mathrm{CIU}=$ chronic idiopathic urticaria.

The prevalence of medical claims for asthma (25.8\% vs. $43.3 \%$ vs. $35.6 \%)$ increased significantly in the post-index period, especially in the 1- to 6-month post-index period compared with baseline (for all comparisons, $P<0.001$ ), and depression (3.0\% vs. 6.4\%) increased significantly in the 7- to 12 -month post-index period compared to baseline $(P<0.05)$. The prevalence of health care encounters coded for idiopathic urticaria (49.0\% vs. $60.4 \%$ vs. $60.4 \%$ ) increased significantly, while dermatographic urticaria $(7.7 \%$ vs. $4.0 \%$ vs. $4.4 \%)$ and unspecified urticaria $(53.0 \%$ vs. $39.3 \%$ vs. $30.5 \%)$ decreased significantly $(P<0.05)$ from baseline through the 1- to 6 -month and 7 - to 12 -month post-index periods, respectively. The prevalence of medical claims for allergic urticaria (22.8\% vs. $13.4 \%$ ) decreased significantly in the 7 - to 12 -month post-index period compared to baseline $(P<0.001)$, as shown in Table 2. Similar trends were observed in patients with $\geq 18$ months of postindex follow-up and continued over the longer follow-up time period, as shown in Appendix A.

Laboratory Evaluations. The percentage of patients with a claim for a complete blood count with differential (48.3\% vs.
$30.2 \%$ vs. $31.9 \%)$, erythrocyte sedimentation rate $(30.2 \%$ vs $9.7 \%$ vs. $12.1 \%)$, and thyroid antibody test $(23.8 \%$ vs. $5.7 \%$ vs. $5.4 \%$ ) decreased significantly across the pre-index baseline period and the 1- to 6-month and 7-to 12-month post-index time periods, respectively (for all comparisons, $P<0.001$ ), as shown in Table 2. Similar trends were observed in patients with $\geq 18$ months of post-index follow-up and continued over the longer follow-up time period, as shown in Appendix A.

\section{Pre- and Post-Index Concomitant Medication Use}

The use of concomitant medications decreased significantly $(P<0.001)$ from baseline through the 1 - to 6 -month and 7 - to 12 -month post-index periods, respectively, including prescription $\mathrm{Hl}$ antihistamines ( $44.0 \%$ vs. $33.6 \%$ vs. $21.5 \%$ ) and prescription $\mathrm{H} 2$ histamines ( $31.5 \%$ vs. $20.1 \%$ vs. $15.1 \%$ ), as shown in Figure 1. Significant decreases were also reported at baseline versus 1 - to 6 -month and 7-to 12 -month post-index periods, respectively, for montelukast $(51.0 \%$ vs. $36.6 \%$ vs. $26.2 \%$ ), cyclosporine ( $8.1 \%$ vs. $4.4 \%$ vs. $2.0 \%$ ), and oral corticosteroids (62.1\% vs. $39.3 \%$ vs. $28.2 \%$; all $P<0.05$ ). Similar trends were 

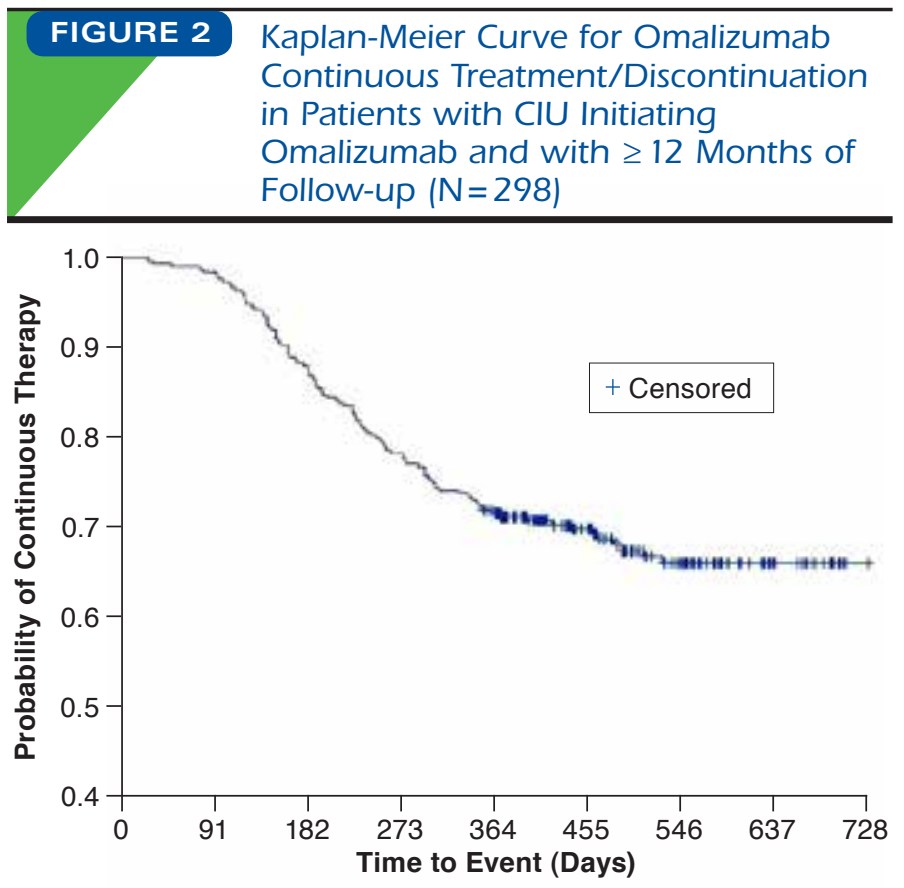

\begin{tabular}{|c|c|c|c|c|c|c|c|c|c|}
\hline $\begin{array}{r}\text { patients } \\
\text { at risk }\end{array}$ & 298 & 293 & 262 & 232 & 213 & 136 & 84 & 27 & 3 \\
\hline
\end{tabular}

CIU = chronic idiopathic urticaria.

observed in patients with $\geq 18$ months of post-index follow-up and continued over the longer follow-up time period as shown in Appendix B (available in online article).

\section{Omalizumab Utilization Patterns}

Duration of Continuous Treatment. Overall, more than $70 \%$ of patients who started omalizumab treatment remained on therapy for at least 1 year, with the majority staying on for approximately 15 months. As the Kaplan-Meier analysis showed, among 298 patients with $\geq 12$ months of post-index follow-up, the mean (95\% confidence interval [CI]) number of days of continuous treatment with omalizumab was 443.1 (425.0-461.3). The probabilities of patients receiving continuous treatment (95\% CI) were 0.879 (0.836-0.911), 0.711 (0.656$0.759)$, and 0.647 (0.585-0.703) for the 6-, 12-, and 18-month post-index periods, respectively, as shown in Figure 2 . For patients with $\geq 18$ months of post-index follow-up, the mean $(95 \% \mathrm{CI})$ number of days of continuous treatment with omalizumab was 428.4 (400.5-456.4). The probability of continuous treatment $(95 \% \mathrm{CI})$ within the 6-, 12-, and 18-month post-index periods, respectively, was 0.855 (0.784-0.904), 0.674 (0.589-0.745), and 0.601 (0.515-0.678; data not shown).
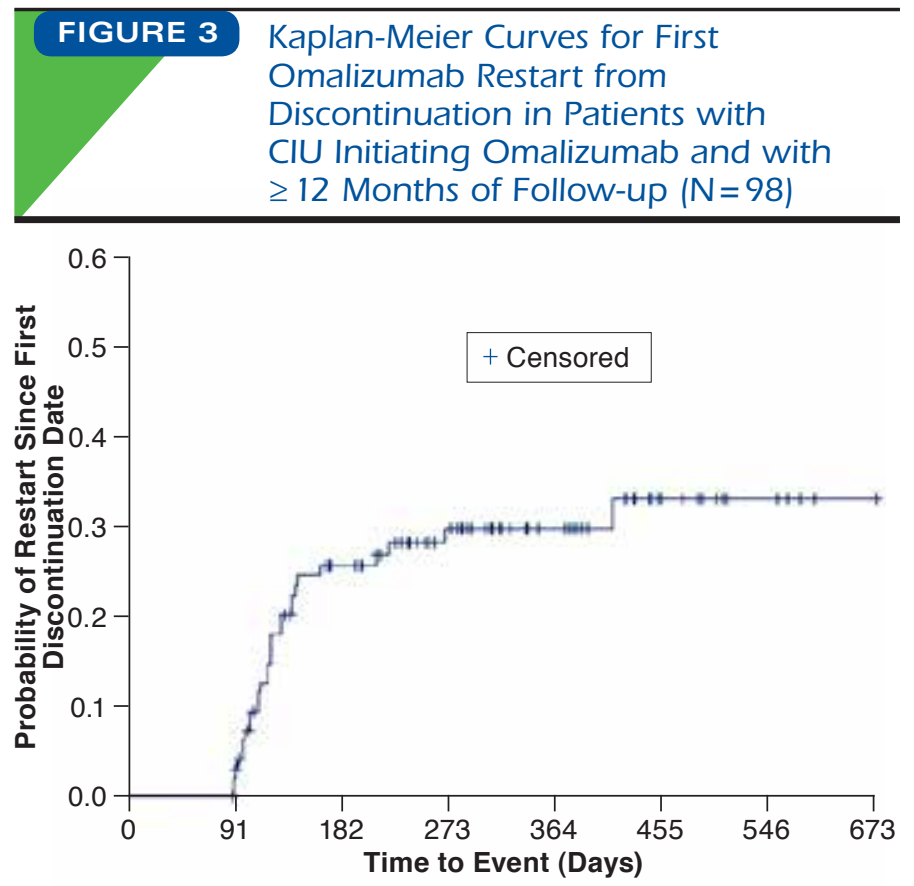

$\begin{array}{r}\begin{array}{r}\begin{array}{r}N \text { of } \\ \text { patients } \\ \text { at risk }\end{array}\end{array} 98 \\ \hline\end{array}$

$C I U=$ chronic idiopathic urticaria.

Discontinuation. For patients with $\geq 12$ months of post-index follow-up, 12.1\% ( $\mathrm{n}=36), 28.5 \%(\mathrm{n}=85)$, and $32.9 \%(\mathrm{n}=98)$ discontinued omalizumab within the 6-month, 12-month, and the entire post-index periods (mean 530 days), respectively. Among the patients with $\geq 18$ months of post-index follow-up, omalizumab was discontinued in $14.5 \%(n=20), 31.9 \%$ $(n=44), 39.9 \%(n=55)$, and $39.9 \%(n=55)$ of patients within the 6-month, 12-month, 18-month, and the entire post-index periods, respectively.

Restart. Among the 98 patients with $\geq 12$ months of postindex follow-up who discontinued omalizumab within the entire post-index period, $28.6 \%$ restarted omalizumab after the first treatment interruption. Among 55 patients with $\geq 18$ months of post-index follow-up who discontinued omalizumab within the entire post-index period, $32.7 \%$ restarted omalizumab after the first treatment interruption. The Kaplan-Meier analysis results for the $\geq 12$-month follow-up cohort showed that the mean $(95 \% \mathrm{CI})$ number of days from first discontinuation to first restart was 328.8 (301.3-356.2) during the entire post-index period and the probabilities of restart (95\% CI) was 0.260 (0.182-0.363), $0.301(0.216-0.409)$, and 0.334 (0.236-0.459) within the 6-, 12-, and 18-month periods since first discontinuation, respectively, as shown in Figure 3. For 
the $\geq 18$-month follow-up cohort, the mean (95\% CI) number of days from first discontinuation to first restart was 320.5 (282.8-358.1) during the entire post-index period and the probability of restart $(95 \% \mathrm{CI})$ were $0.301(0.196-0.444), 0.321$ (0.213-0.465), and $0.353(0.237-0.505)$ within the 6-, 12-, and 18-month periods since first discontinuation, respectively (data not shown).

\section{Sensitivity Analysis}

The results from the sensitivity analysis regarding omalizumab continuous treatment, discontinuation, and restart using a gap of $\geq 60$ days between omalizumab administrations/fills were similar to the main analysis results (data not shown).

\section{Discussion}

Omalizumab has been prescribed to patients for over 15 years and has been indicated for the management of CIU since 2014.12 Not unexpectedly, due to the short time since the approval for the CIU indication, real-word data on the use of omalizumab among these patients are sparse, and only the results of a few short-term studies that evaluated small patient samples are currently available.

This study presents real-world information on the demographic and clinical characteristics and treatment patterns of CIU patients initiating omalizumab treatment. ${ }^{7}$ The study concentrated on results for patients who had $\geq 12$ months of follow-up data; results are also shown for a subgroup of patients whose information was available for $\geq 18$ months after treatment initiation. The longer follow-up in the present study adds information on treatment patterns in usual care and complements evidence generated in the randomized controlled trials, which typically had follow-up periods that were no longer than 6 months. These data with longer follow-up can provide valuable information with regard to the real-world duration of therapy that has been described as lacking in the omalizumab package insert. One of the key new insights from this study was that the probability of continuous treatment was high across the post-index period: the mean duration of continuous treatment for patients with $\geq 12$ months of postindex follow-up was 443 days and 428 days for patients with $\geq 18$ months of follow-up.

A handful of retrospective studies have evaluated the use of omalizumab in usual care settings and reported on response and discontinuation rates and reasons for discontinuation, continuous treatment, resolution of symptoms, and time to relapse..$^{3,5,17-19}$ In most cases the studies used relatively small sample sizes, had short follow-up periods ranging from 8 weeks to 7 months, ${ }^{5,19,21}$ or were performed outside the United States. In one U.S.-based retrospective chart review study, among CIU patients receiving omalizumab for more than 1 year, 10 patients were assessed to determine the effectiveness of omalizumab, the feasibility of weaning patients off treatment, and safety associated with refractory disease. The authors concluded that it was safe and effective for patients with refractive CIU to receive omalizumab for more than 1 year but suggested periodic weaning to allow for opportunities for spontaneous remission. ${ }^{18}$ A research letter on one Danish study $(\mathrm{N}=154)$ reported that $56.2 \%$ of patients continued treatment 1 year after treatment initiation. ${ }^{21}$ For these and other reasons, including substantially different study designs and care settings, it is not instructive to make comparisons with our findings, which are based on a substantially longer follow-up duration. Har et al. (2015), in a study $(\mathrm{N}=10)$ that evaluated the effectiveness, safety, and feasibility of weaning omalizumab, reported that patients stayed on omalizumab therapy for 17-112 (median 27) months. ${ }^{18}$

Of note in our study, most patients (approximately 84\%) were seen by allergists or immunologists, while only a small proportion $(\sim 6 \%)$ were seen by dermatologists. This information is not well characterized in the handful of retrospective studies in the literature. These studies did not report provider specialities and were largely conducted with convenience samples, often of specific patients in a single clinical practice, $5,18,19,21$ unlike our study, which sampled a large spectrum of commercially insured and Medicare Advantage patients.

CIU patients initiating treatment with omalizumab used significantly fewer other related medications in the post-index period relative to the baseline pre-index period. Most noteworthy is that oral corticosteroid use decreased by more than half from the baseline period to 1 year after starting omalizumab. This could be considered as a proxy for a decrease in CIU symptoms after omalizumab. Similar decreases were observed for montelukast and prescription $\mathrm{H} 1$ and $\mathrm{H} 2$ antihistamines. This is beneficial to CIU patients, since it decreases their medication burden and limits the long-term risks of adverse effects associated with medications such as oral corticosteroids.

Overall, almost three quarters of patients continued omalizumab therapy within the 12-month post-index period during the main analyses and approximately 60\% within the 18 -month post-index period among the subset of patients with $\geq 18$ months of follow-up. Among patients with first omalizumab discontinuation, less than one third of patients restarted omalizumab treatment after their first discontinuation during the entire post-index period. The time between discontinuation and restart was almost a year (329 days) for patients who were re-treated. As CIU is a condition that commonly reappears and omalizumab is not a remittive therapy, recurrence was not unexpected. While clinical studies also report discontinuation rates, ${ }^{14,16,22}$ our results add to these data captured in the controlled settings of clinical trials. However, administrative claims data do not provide reasons why patients discontinue their treatment, although the range of possibilities may include treatment efficacy, disease remission, or intolerance due to adverse effects. 


\section{Limitations}

As with any study, limitations with regard to data source and study design should be taken into account when interpreting the results. The presence of a diagnosis code on a medical claim is not a guarantee of the presence of the disease of interest. Coding could be erroneously applied or used as a ruleout criterion. In particular with CIU, no classification option is available for defining chronicity of idiopathic urticaria in ICD-9-CM/ICD-10-CM diagnosis codes. Since all urticaria diagnosis codes were used for the identification of CIU patients, some study patients could have been misclassified as CIU patients. This was likely mitigated, however, by prior authorization models in the health plans that require the presence of CIU before omalizumab was prescribed. In addition, a significant number of patients had a concomitant diagnosis of asthma, so we cannot definitely determine the indication for administration of omalizumab in these patients. Over-thecounter medications or provider samples are not captured in the claims data, so medication use could have been underestimated, which is especially relevant when evaluating our reported use of $\mathrm{H} 1$ and $\mathrm{H} 2$ antihistamines, as only prescription use could be captured. Dosing information for omalizumab was unavailable in the claims data. Since only patients treated with $\geq 4$ claims for omalizumab within 6 months after initiation were included, the study sample was likely different from populations with $<4$ claims for omalizumab. We chose this selection criteria to ensure that we evaluated only patients who were provided omalizumab therapy that was sufficient for a meaningful determination of effect. Study patients were identified within administrative claims in one large U.S.based repository and consisted of commercial and Medicare Advantage health plan enrollees, potentially limiting the generalizability of these results across different populations.

\section{Conclusions}

In this cohort of CIU patients who were prescribed omalizumab therapy, the majority of patients were treated by allergists/ immunologists, and approximately $60 \%$ of patients persisted on omalizumab treatment for at least 18 months. Concomitant medication use decreased after omalizumab initiation. As these are among the first data available from the real-world use of omalizumab for CIU, this information may help providers as they develop their treatment plans and provide expectations on the treatment course, as well as to better inform decisionmaking processes for health care payers.

\section{Authors}

XUEHUA KE, PhD; DEBRA WERTZ, PharmD; QING HUANG, PhD; LIYA WANG, PhD; VINCENT J. WILLEY, PharmD; and JUDITH J. STEPHENSON, SM, HealthCore, Wilmington, Delaware. ABHISHEK KAVATI, PhD; BENJAMIN ORTIZ, MD; and BRANDEE PAKNIS, PharmD, Novartis Pharmaceuticals, East Hanover, New Jersey. JONATHAN A. BERNSTEIN, MD, Bernstein Clinical Research Center, Cincinnati, Ohio, and LISA A. BECK, MD, University of Rochester Medical Center, Rochester, New York.

AUTHOR CORRESPONDENCE: Xuehua Ke, PhD, HealthCore, 123 Justison St., Ste. 200, Wilmington, DE 19801.

Tel.:302.230.2159; Email: xke@healthcore.com.

\section{DISCLOSURES}

This study was sponsored by Novartis Pharmaceuticals, which provided funding support for the conduct of the study. Kavati, Ortiz, and Paknis are employees of Novartis Pharmaceuticals. Ke, Wertz, Huang, Wang, Willey, and Stephenson are employees of HealthCore, an independent research organization that received funding from Novartis Pharmaceuticals for the conduct of this study. Beck is an employee of the University of Rochester Medical Center, who was under contract with Novartis Pharmaceuticals to provide consulting services to this study, and reports grants from Genentech, outside the currently submitted work. Bernstein is affiliated with Bernstein Clinical Research Center, which was under contract with Novartis Pharmaceuticals to provide consulting services to this study, and reports receiving grants and personal fees from Novartis Pharmaceuticals, grants and personal fees from Genentech outside of the submitted work, and is an author on the Joint Task Force for Practice Parameters for Urticaria and the GALEN international guidelines for urticaria under preparation.

Selected study data were presented in a poster at the International Society for Pharmacoeconomics and Outcomes Research (ISPOR) 22nd Annual International Meeting on May 20-24, 2017, in Boston, MA. A poster based on this dataset was presented at the 2017 American College of Allergy, Asthma \& Immunology (ACAAI) Annual Scientific Meeting on October 26-30, 2017, in Boston, MA

\section{ACKNOWLEDGMENTS}

B. Bernard Tulsi, MSc, provided writing and editorial support for this project.

\section{REFERENCES}

1. Zuberbier T, Asero R, Bindslev-Jensen C, et al. EAACI/GA(2)LEN/EDF/ WAO guideline: management of urticaria. Allergy. 2009;64(10):1427-43.

2. Moolani Y, Lynde C, Sussman G. Advances in understanding and managing chronic urticaria. F1000Res. 2016;5:177. Available at: https://www.ncbi. nlm.nih.gov/pmc/articles/PMC4756797/. Accessed December 4, 2017.

3. Asthma and Allergy Foundation of America (AAFA). CIU \& you. Available at: http://www.aafa.org/page/ciu-you.aspx. Accessed December 1, 2017.

4. Maurer M, Weller K, Bindslev-Jensen C, et al. Unmet clinical needs in chronic spontaneous urticaria. A GA(2)LEN task force report. Allergy. 2011;66(3):317-30.

5. Metz M, Ohanyan T, Church MK, Maurer M. Retreatment with omalizumab results in rapid remission in chronic spontaneous and inducible urticaria. JAMA Dermatol. 2014;150(3):288-90.

6. U.S. Census Bureau. Census regions and divisions of the United States. Available at: http://www2.census.gov/geo/pdfs/maps-data/maps/reference/ us_regdiv.pdf. Accessed December 1, 2017. 
7. Kaplan A, Ferrer M, Bernstein JA, et al. Timing and duration of omalizumab response in patients with chronic idiopathic/spontaneous urticaria. J Allergy Clin Immunol. 2016;137(2):474-81.

8. Bernstein JA, Lang DM, Khan DA, et al. The diagnosis and management of acute and chronic urticaria: 2014 update. J Allergy Clin Immunol. 2014;133(5):1270-77.

9. Fine LM, Bernstein JA. Guideline of chronic urticaria beyond. Allergy Asthma Immunol Res. 2016;8(5):396-403.

10. Deacock SJ. An approach to the patient with urticaria. Clin Exp Immunol. 2008;153(2):151-61.

11. Maurer M, Altrichter S, Bieber T, et al. Efficacy and safety of omalizumab in patients with chronic urticaria who exhibit IgE against thyroperoxidase. J Allergy Clin Immunol. 2011;128(1):202-09.e05.

12. Xolair (omalizumab) for injection, for subcutaneous use. Genentech. June 2017. Available at: http://www.gene.com/download/pdf/xolair_prescribing.pdf. Accessed December 1, 2017.

13. Saini S, Rosen KE, Hsieh HJ, et al. A randomized, placebo-controlled, dose-ranging study of single dose omalizumab in patients with Hl-antihistamine-refractory chronic idiopathic urticaria. J Allergy Clin Immunol. 2011;128(3):567-73.e61.

14. Maurer M, Rosen K, Hsieh HJ, et al. Omalizumab for the treatment of chronic idiopathic or spontaneous urticaria. N Engl J Med. 2013;368(10):924-35.

15. Kaplan A, Ledford D, Ashby M, et al. Omalizumab in patients with symptomatic chronic idiopathic/spontaneous urticaria despite standard combination therapy. J Allergy Clin Immunol. 2013;132(1):101-09.
16. Saini SS, Bindslev-Jensen C, Maurer M, et al. Efficacy and safety of omalizumab in patients with chronic idiopathic/spontaneous urticaria who remain symptomatic on $\mathrm{Hl}$ antihistamines: a randomized, placebo-controlled study. J Invest Dermatol. 2015;135(1):67-75.

17. Ghazanfar MN, Sand C, Thomsen SF. Effectiveness and safety of omalizumab in chronic spontaneous or inducible urticaria: evaluation of 154 patients. Br J Dermatol. 2016;175(2):404-06.

18. Har D, Patel S, Khan DA. Outcomes of using omalizumab for more than 1 year in refractory chronic urticaria. Ann Allergy Asthma Immunol. 2015;115(2):126-29.

19. Metz M, Ohanyan T, Church MK, Maurer M. Omalizumab is an effective and rapidly acting therapy in difficult-to-treat chronic urticaria: a retrospective clinical analysis. J Dermatol Sci. 2014;73(1):57-62.

20. Wasser T, Wu B, Ycas J, Tunceli O. Applying weighting methodologies to a commercial database to project US census demographic data. Am J Accountable Care. 2015;33-38. Available at: http://www.ajmc.com/ journals/ajac/2015/2015-vol3-n3/applying-weighting-methodologies-to-acommercial-database-to-project-us-census-demographic-data/p-2. Accessed December 1, 2017.

21. Ghazanfar MN, Sand C, Thomsen SF. Effectiveness and safety of omalizumab in chronic spontaneous or inducible urticaria: evaluation of 154 patients. Br J Dermatol. 2016;175(2):404-06.

22. Zhao ZT, Ji CM, Yu WJ, et al. Omalizumab for the treatment of chronic spontaneous urticaria: a meta-analysis of randomized clinical trials. J Allergy Clin Immunol. 2016;137(6):1742-50.e44. 
APPENDIX A Pre- and Post-Index Clinical Characteristics in Patients with CIU Initiating Omalizumab and with $\geq 18$ Months of Post-Index Follow-up ( $N=138$ )

\begin{tabular}{|c|c|c|c|c|c|c|c|}
\hline Clinical Characteristics & $\begin{array}{c}6 \text { Months } \\
\text { Pre-Index (A) }\end{array}$ & $\begin{array}{c}6 \text { Months } \\
\text { Post-Index (B) }\end{array}$ & $\begin{array}{l}\text { 7-12 Months } \\
\text { Post-Index (C) }\end{array}$ & $\begin{array}{l}\text { 13-18 Months } \\
\text { Post-Index (D) }\end{array}$ & $\begin{array}{l}P \text { Value } \\
\text { (A vs. B) }\end{array}$ & $\begin{array}{l}\text { P Value } \\
\text { (A vs. C) }\end{array}$ & $\begin{array}{l}P \text { Value } \\
(A \text { vs. D) }\end{array}$ \\
\hline \multicolumn{5}{|c|}{ Prescribing/treating physician specialty, ${ }^{\mathrm{b}} \mathrm{n}(\%)$} & 0.384 & 0.541 & 0.050 \\
\hline Allergist/immunologist & $113(81.9)$ & $117(84.8)$ & $108(78.3)$ & $99(71.7)$ & 0.248 & 0.251 & 0.011 \\
\hline Dermatologist & $8 \quad(5.8)$ & $4 \quad(2.9)$ & $6 \quad(4.3)$ & $6 \quad(4.3)$ & 0.102 & 0.317 & 0.527 \\
\hline PCP & $4 \quad(2.9)$ & $1 \quad(0.7)$ & $3(2.2)$ & $3(2.2)$ & 0.180 & 0.705 & 0.705 \\
\hline Others & $8 \quad(5.8)$ & $7 \quad(5.1)$ & $9 \quad(6.5)$ & $8 \quad(5.8)$ & 0.655 & 0.739 & 1.000 \\
\hline Unknown & $5 \quad(3.6)$ & $9 \quad(6.5)$ & $12(8.7)$ & $22(15.9)$ & 0.046 & 0.035 & $<0.001$ \\
\hline \multicolumn{8}{|l|}{ Comorbidities of interest, $\mathrm{n}(\%)$} \\
\hline Allergic rhinitis & $69(50.0)$ & $60(43.5)$ & $56(40.6)$ & $55(39.9)$ & 0.095 & 0.020 & 0.020 \\
\hline Anaphylaxis & $7 \quad(5.1)$ & $0 \quad(0.0)$ & $1 \quad(0.7)$ & $2(1.4)$ & 0.008 & 0.014 & 0.096 \\
\hline Conjunctivitis & $7 \quad(5.1)$ & $10 \quad(7.2)$ & $6 \quad(4.3)$ & $7 \quad(5.1)$ & 0.366 & 0.763 & 1.000 \\
\hline Eczema/dermatitis & $29(21.0)$ & $24(17.4)$ & $20(14.5)$ & $20(14.5)$ & 0.336 & 0.072 & 0.139 \\
\hline Food allergy & $9 \quad(6.5)$ & $6 \quad(4.3)$ & $2 \quad(1.4)$ & $3(2.2)$ & 0.257 & 0.008 & 0.014 \\
\hline Angioedema & $36(26.1)$ & $22(15.9)$ & $16(11.6)$ & $13 \quad(9.4)$ & 0.006 & $<0.001$ & $<0.001$ \\
\hline Asthma & $37(26.8)$ & $59(42.8)$ & $51(37.0)$ & $46(33.3)$ & $<0.001$ & 0.013 & 0.106 \\
\hline COPD & $1 \quad(0.7)$ & $1 \quad(0.7)$ & $1 \quad(0.7)$ & $1 \quad(0.7)$ & - & - & - \\
\hline Anxiety & $14(10.1)$ & $13 \quad(9.4)$ & $10 \quad(7.2)$ & $9 \quad(6.5)$ & 0.796 & 0.248 & 0.197 \\
\hline Depression & $3(2.2)$ & $2 \quad(1.4)$ & $4 \quad(2.9)$ & $17(12.3)$ & 0.564 & 0.564 & $<0.001$ \\
\hline Vasculitis and allergic purpura & $0 \quad(0.0)$ & $0 \quad(0.0)$ & $2 \quad(1.4)$ & $2(1.4)$ & - & 0.157 & 0.157 \\
\hline \multicolumn{8}{|c|}{ Breakdown categories of urticaria, ${ }^{\mathrm{c}} \mathbf{n}(\%)$} \\
\hline Overall urticaria & $130(94.2)$ & $134(97.1)$ & $121(87.7)$ & $116(84.1)$ & 0.157 & 0.050 & 0.006 \\
\hline Allergic urticaria & $38(27.5)$ & $26(18.8)$ & $17(12.3)$ & $16(11.6)$ & 0.046 & $<0.001$ & $<0.001$ \\
\hline Idiopathic urticaria & $63(45.7)$ & $83(60.1)$ & $76(55.1)$ & $84(60.9)$ & 0.001 & 0.042 & 0.006 \\
\hline Urticaria due to cold and heat & $1 \quad(0.7)$ & $0 \quad(0.0)$ & $0 \quad(0.0)$ & $0 \quad(0.0)$ & 0.317 & 0.317 & 0.317 \\
\hline Dermatographic urticaria & $10 \quad(7.2)$ & $3(2.2)$ & $6 \quad(4.3)$ & $5 \quad(3.6)$ & 0.020 & 0.248 & 0.166 \\
\hline Vibratory urticaria & $0 \quad(0.0)$ & $0 \quad(0.0)$ & $0 \quad(0.0)$ & $0 \quad(0.0)$ & - & - & - \\
\hline Cholinergic urticaria & $3(2.2)$ & $2 \quad(1.4)$ & $2 \quad(1.4)$ & $2 \quad(1.4)$ & 0.564 & 0.564 & 0.655 \\
\hline Other specified urticaria & $71 \quad(51.4)$ & $66(47.8)$ & $55(39.9)$ & $54(39.1)$ & 0.369 & 0.008 & 0.013 \\
\hline Urticaria, unspecified & $71(51.4)$ & $54(39.1)$ & $38(27.5)$ & $36(26.1)$ & 0.017 & $<0.001$ & $<0.001$ \\
\hline \multicolumn{8}{|l|}{ Laboratory tests of interest, $\mathrm{n}(\%)$} \\
\hline $\mathrm{CBC}$ test & $69(50.0)$ & $41(29.7)$ & $44(31.9)$ & $35(25.4)$ & $<0.001$ & 0.001 & $<0.001$ \\
\hline ESR test & $35(25.4)$ & $11(8.0)$ & $17(12.3)$ & $15(10.9)$ & $<0.001$ & 0.004 & 0.001 \\
\hline Thyroid antibody test & $28(20.3)$ & $8 \quad(5.8)$ & $11 \quad(8.0)$ & $7 \quad(5.1)$ & $<0.001$ & 0.001 & $<0.001$ \\
\hline \multicolumn{8}{|c|}{$\begin{array}{l}\text { aP values were estimated from paired t-tests or Wilcoxon signed-rank sum tests for normally distributed and non-normally distributed continuous variables, respectively, } \\
\text { and from McNemar tests (or Bowker's tests of symmetry for square tables larger than } 2 \times 2 \text { ) for categorical variables. } \\
\text { bThe following hierarchy was applied when multiple specialties existed: allergy/immunology }>\text { dermatology }>\text { family/general practice }>\text { internal medicine }>\text { others or } \\
\text { unknown. PCP includes family/general practice and internal medicine. } \\
\text { 'All patients had urticaria claims during the study period; however, not all patients had urticaria claims during both the pre-index and post-index periods reported here. } \\
C B C=\text { complete blood count with differential; CIU =chronic idiopathic urticaria; COPD =chronic obstructive pulmonary disease; ESR=erythrocyte sedimentation rate; } \\
P C P=\text { primary care physician. }\end{array}$} \\
\hline
\end{tabular}


APPENDIX B Pre- and Post-Index Concomitant Medication Use in Patients with CIU Initiating Omalizumab and with $\geq 18$ Months of Post-Index Follow-up ( $N=138)$

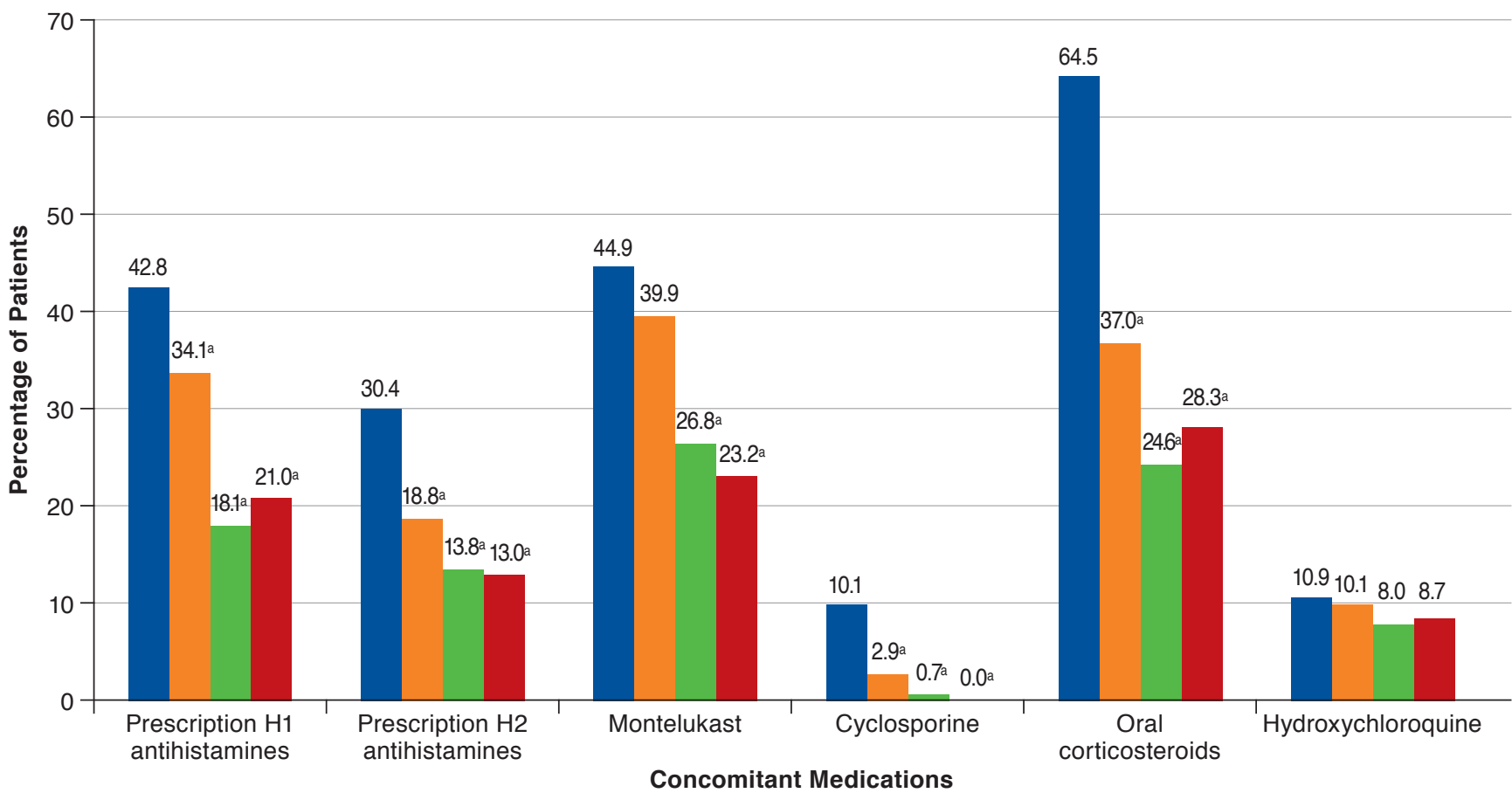
6 months pre-index
6 months post-index
7-12 months post-index
13-18 months post-index

${ }^{a} P<0.05$ when comparing post-index to pre-index periods.

$\mathrm{CIU}=$ chronic idiopathic urticaria. 